\title{
ACESSOS, SENTIDOS E SIGNIFICADOS PARA MENINA E MOÇA, DE BERNARDIM RIBEIRO
}

Tatiana Pequeno*

RESUMO: O presente artigo deriva de alguns questionamentos relativos ao universo da obra Menina e Moça, de Bernardim Ribeiro. Tal como se apresenta, o livro indeterminado do autor quinhentista funciona como marco nodular da literatura portuguesa, na medida em que configura estratégias de passagem não só de um universo medieval subscrito no tom de queixa das antigas cantigas, como também apresenta questionamentos da ordem do ser e da sua existência, que podem ser radicalizados na seguida poética camoniana, por exemplo, definindo desse modo alguns dos pilares do Renascimento e do começo histórico da ldade Moderna. Apesar de localizado nesse entre-lugar em que quaisquer definições de estilo parecem insuficientes, tencionamos buscar aportes teóricos para alguma análise da referida obra em dois nomes contemporâneos, a sabe o filósofo italiano Giorgio Agamben, e o crítico literário e o escritor português Helder Macedo.

PALAVRAS-CHAVE: Bernardim Ribeiro; Menina e Moça; Literatura Portuguesa.
* tatianapequeno@gmail.com

Doutora em Letras Vernáculas (Literaturas Portuguesa e Africanas) pela UFRJ.

RÉSUMÉ: Cet article veux penser quelques questions relatives au monde du travail Menina e Moça, de Bernardim Ribeiro. À l'heure actuelle, l'auteur du XVle fonctions indéterminées du livre comme une nodulaire marque de la littérature portugaise, en ce qu'elle fixe des stratégies passage non seulement d'un univers médiéval, souscrit à se plaindre ton des vieilles chansons, mais aussi présente des questions d'ordre être et l'existence, qui peut ensuite être radicalisé dans Camões poétiques, par exemple, de manière à définir certains des piliers de la Renaissance et l'histoire des débuts de l'ère moderne. Bien que situé en entre le lieu où toutes les définitions de style semblent insuffisantes, nous avons l'intention de solliciter un appui théorique pour une analyse de ce travail dans deux noms contemporains, à savoir le philosophe italien Giorgio Agamben, critique littéraire et I'écrivain portugais Helder Macedo.

MOTS-CLÉS: Bernardim Ribeiro; Menina e Moça; Littérature Portugaise. 


\section{UNS TEMPOS COM GRAND'ENGANO}

Menina e moça me levaram de casa de meus pais para longes terras e qual fosse a causa dessa minha levada, era pequena, não na soube.

Bernardim Ribeiro, Menina e Moça ou Saudades.

A meio do caminho a mais de meia vida já vivid reencontrei-me só na selva escura da vida indecifrad

e não sei de que lado está a mort não sei se é $o$ amor quem a sustenta

no tempo

de destruir

para ver o que seja o que me sobra

no certo entendimento

de que as vidas são feitas no perdê-las

ou nisso só existe

porque há vida somente quando há morte e porque toda a selva por mais cerrada e escura

contém o tempo já do seu deserto

na fértil luz difusa que a penetra

para nela executar o seu amor.

Helder Macedo. Viagem de Inverno.
O Menina e Moça é, sem sombra de dúvidas, um dos livros mais instigantes da literatura portuguesa. Dizer isto é também concordar que juntamente às crônicas de Fernão Lopes, a prosa de Bernardim Ribeiro enceta uma passagem não de natureza apenas histórica, mas sobretudo, estética. O lugar desta obra no contexto literário português é sempre uma aposta na atualização da tradição, uma vez que neste texto do século XVI vislumbram-se linhas mestras da temática lusófona: a melancolia, o exílio, a viagem. No texto bernardiniano, no entanto, estas linhas de força não se apresentam de forma tão evidente e portanto é preciso desfazer os nós do modo como Maria Gabriela Llansol sugere em Um Falcão no punho: não frontalmente. Desse modo, pensamos neste artigo não como introdutor ou chave de leitura, mas como proposta de acesso que dialoga diretamente com uma crítica já referendada do livro. Apesar de quase todo texto teórico sobre o Menina e Moça começar com uma afirmativa que assinala o sentido misterioso do romance, cabe aqui mencionarmos que o presente artigo é sobretudo um debruçamento na investigação que Helder Macedo desenvolve sobre os plurais níveis exegéticos que o livro de Bernardim enseja e o crítico discute em Do significado oculto da Menina e Moça.

Como ler Menina e Moça, como estabelecer um pacto de leitura com este texto que não se evidencia de maneira lógica enquanto narrativa? Não seria esta - a resistência a um 
significado linear - uma das condiçoes da própria literatura? A partir do problema relativo a uma camada plural de significados que existe nas várias interpretações que lhe cabem preferimos encaminhar nossa reflexão discutindo alguns pontos levantados nos textos que compõem a obra Viagens do Olhar, de Helder Macedo, e adiante seguimos com uma leitura mais específica do título que condiciona esta proposta: Do Significado Oculto da Menina e Moça, na medida em que tencionamos articular aqui as tensões oriundas do problema do significado atrelado ao fator legibilidade.

Os problemas que se relacionam ao aspecto do significado ocidental relativo à Arte podem ser já estruturalmente repensados por meio do livro de Bernardim Ribeiro, também porque seu corpo textual fragmentário orienta questões de natureza contemporânea: a que gênero literário pertenceria a narrativa? Assim sendo, nosso interesse principal é investigar o amalgamento de problemas que norteiam o estabelecimento dos gêneros literários, como por exemplo o excesso de lirismo existente nesse "romance" que tanto se aproxima do tom queixoso das cantigas medievais, conforme aponta Helder Macedo na introdução de sua edição para o livro:

Só que, tratando-se de poesia, de romance (e, para mais, de um romance que, sintáctica e estruturalmente, deve tanto à poesia que pode, sem incompatibilidade, recorrer a poemas para marcar três momentos cruciais da narrativa), a confissão tende a exprimir-se através de metáforas e a autobiografia através da sua transposição em personagens colocadas em situações fictícias ${ }^{1}$.

Dessa forma, parece-nos conveniente começar tal reflexão a partir de uma problemática de feições atuais, já que a leitura que propomos é a que se localiza, com efeito, nos pressupostos estéticos e literários dos séculos XX e XXI.

Para alguns filósofos contemporâneos, um dos temas mais interessantes parece ser o da problemática do significado no contexto da arte hodierna. É portanto notório que a dificuldade de legibilidade de um texto apareça como questão filosófica, uma vez que para a literatura e para a filosofia, a linguagem é um problema carregado de potências. Como então apresentar o problema da legibilidade de um livro do século $\mathrm{XVI}^{2}$ ? De acordo com Giorgio Agamben, o permanente estado de hesitação de um texto em prosa capacitaria esse texto a se apresentar como poético, sobretudo porque para o pensador italiano a idéia da versura é extremamente conveniente para se entender a literatura depois das raízes fincadas pelos trovadores medievais. Para além disso, convém lembrar que os traços literários das cantigas ainda aparecem muito sensivelmente no livro de Bernardim Ribeiro, de acordo com o que demonstra Helder Macedo em "As obscuras transparências de Bernardim Ribeiro" de Viagens do Olhar. Para
2. RIBEIRO. Menina e Moça ou Saudades, p. 26.
3. É importante aqui mencionar que não é interesse deste trabalho problematizar as questões filológicas e de ordem da crítica genética e textual relativas ao Menina e Moça. 
4. AGAMBEN. "O fim do poema”, p. 143.
Macedo, o caráter de duplicação semântica reside não apenas nos pares divisores da história (Lamentor/ Belisa, Aónia/ Bimarder e Avalor/ Arima), mas também na continuidade estabelecida pelo leixa-pren que marcava ocasionalmente a estrutura das cantigas paralelísticas. Essa estruturação formulada pelo eminente crítico português pode dialogar com as proposições de Agamben sobre a formulação clássica de Valéry: "Le poème, hésitation prolonguée entre le son et le sens", ao se referir à questão nodular da poesia a partir do embate entre a segmentação métrica e a semântica, que corroboraria com a leitura de H. Macedo:

E o poema é um organismo que se funda sobre a percepção de limites e terminações, que definem, sem jamais coincidir completamente e quase em oposta divergência - unidades sonoras (ou gráficas) e unidades semânticas [...] Podemos contar as sílabas e os acentos, verificar as sinalefas e as cesuras, classificar anomalias e regularidades: mas o verso é, em qualquer caso, uma unidade que encontra o seu principium individuationis somente no fim, que se define só no ponto em que finda. Em outro trabalho, propus dar o nome de versura - do termo latino que indica o ponto no qual o arado faz a volta, ao final do sulco - a esse traço essencial do verso que, talvez mesmo por ser tão evidente, permaneceu inominado entre os modernos ${ }^{3}$.

Do ponto de vista do sentido, temos aí um bom argumento que sustente a idéia do Menina e Moça poder ser concebido como prosa poética, já que essa hesitação da qua parte Agamben via Valéry funciona como fato no texto de Bernardim Ribeiro: é que essa suspensão encontra eco nos três capítulos nodulares organizados pela edição de Helder Macedo. Ou seja, o mote da versura ocorreria pelas relações de continuidade que existem entre o fato de a história de Lamentor e Belisa se desmembrar nas figuras de Aónia - sua irmã mais nova, e Arima - filha da morte de Belisa.

Entretanto, misturadas ao contexto da constante mudança de que resulta o livro, as duas figuras femininas que entoam o discurso no começo da obra funcionam como elos capazes não só de justificar um significado plausível para a aparente falta de coerência, como também servem para explicar a procedência do contar:

Isto me pôs em dúvida de começar a escrever as coisas que vi e ouvi. Mas depois, cuidando comigo, disse eu que arrecear de não acabar de escrever o que vi não era causa para o deixar de fazer, pois não havia de escrever para ninguém senão para mim só, ante quem coisas não acabadas não havia de ser novo. Que quando vi eu prazer acabado ou mal que tivesse fim? Antes me pareceu que este tempo que hei-de estar assim em este ermo, como ao meu mal aprouve, não o podia empregar em 
5. RIBEIRO. Menina e Moça ou Saudades, p. 77.

6. RIBEIRO. Menina e Moça ou Saudades, p. 87. coisa que mais de minha vontade fosse. Pois Deus quis, assim minha vontade seja ${ }^{4}$.

O que justificaria também o fato de ser um texto perpassado pela mágoa melancólica que acomete o discurso feminino, cifrando-o muitas vezes e interrompendo-o continuamente para reiterar a lógica da dor ao formular, em seguida ao fragmento anteriormente citado, que só os tristes poderão ler o livro, indicando alguma preferência pelo público feminino, uma vez que "sempre nos homens houve desamor". Ora, se consultarmos o que dispomos acerca dos poemas que configuram os cancioneiros medievais, confirmaremos que não só o gênero é imprescindível para a determinação de uma cantiga ser de amor ou amigo, mas também a formulação de uma escrita em ausência: nas cantigas de amor é possível decidir pela inacessibilidade/ impossibilidade dessa presença, enquanto que nas cantigas de amigo notamos uma escrita a partir da falta daquilo que já foi experienciado, devidamente vivido e agora queixado e transformado num discurso muitas vezes repetitivo (vide a "simplicidade" recorrente mais evidente que os críticos atribuem às cantigas de amigo).

Não estamos querendo com isso, limitar a leitura de Bernardim apenas ao universo estilístico e semântico dos Cancioneiros. É notório que concordamos com as proposições de Helder Macedo no texto "Convergências e Dissidências”, em que o crítico apresenta as razões de localização do Menina e Moça como obra pertencente ao tempo das tantas mudanças, em que, notadamente por ser obra de um momento histórico e cultural importantíssimo verifica-se a possibilidade de uma exegese que operacionalize as relações do próprio Bernardim Ribeiro com o universo judaico, a saber pelo fundamental argumento de que a principal edição (Ferrara, 1554) nascera da oficina de um editor cujo pendor de publicação validaria sempre a opção pelos textos de caráter judaico.

Não obstante, parece relevante também mencionar que a melancolia ou "os dias de grande desaventura" confirmam também o leixa-pren do Menina e Moça, já que a autenticação da dor aparece notabilizada, em princípio, nas figuras femininas do prólogo:

Que certamente, segundo as desaventuras são desarrazoadas e graves, aos homens se haviam de fazer, mas quando com eles não puderam, tornaram-se a nós, como à parte mais fraca. Assim que padecemos dois males: um que sofremos, e outro que se não fez para nós. Os homens cuidam outra coisa (mas o que das mulheres não cuidam eles), outra coisa longamente acostumaram: ter em pouco suas tristezas ${ }^{7}$.

O que entretanto pretendemos observar é que tanto a validade da cantiga de amigo, que consolidaria a fala da Menina e também da Dona do tempo antigo como manifestações
7. RIBEIRO. Menina e Moça ou Saudades, p. 96.

8. RIBEIRO. Menina e Moça ou Saudades, p. 91

EM TESE

BELO HORIZONTE

v. 19

N. 3

SET.-DEZ. 2013

PEQUENO. Acessos, sentidos e significados para Menina e Moça [...] P. $42-53$ 
legitimamente femininas, encontraria também contraponto ao fato de a história dos cavaleiros Lamentor, Bimarder e Avalor, poderia conferir ao texto um tom queixoso de marca masculina. Nas cantigas de amor, localizamos não só esse universo de enunciação do masculino, como identificamos uma impossibilidade da concretização do sentimento que o amor-cortês deflagra.

\section{EU SÓ TRISTE EM MINHA MÁGOA}

É evidente que muitas são as proposições de leitura do Menina e Moça. Para que não reduzamos a obra, portanto, a um universo limitado, consideramos relevante apresentar algumas das proposições feitas por Helder Macedo em seu Do Significado Oculto da Menina e Moça.

Macedo parte de uma estratégia que foi por nós esboçada na sessão anterior deste trabalho e parte de uma leitura analítica da própria poesia de Bernardim Ribeiro para construir sua argumentação. Como argumento, o crítico português sugere que o famoso vilancete, a écloga, o romance a sextina (sobre a qual Jorge de Sena já havia inventariado um dualismo contundente) já trazem, em sua essência, toda uma reflexão sobre conceitos e problemas que permearão também a própria "novela sentimental".

A partir dessa leitura, Helder Macedo destaca sete conclusões, a partir das quais formulará todo um cabedal de interpretacões possíveis para o corpus deste nosso presente texto. Outrossim, destacamos algumas das premissas que verdadeiramente nos interessam: o problema do exílio atrelado a um desligamento do sujeito amado; a condição existencial que necessariamente leva o amante a refletir sobre seu estar no mundo; e que o eu enunciador é hipoteticamente sempre um inimigo de si mesmo, já que essa situação concentra uma dualidade relevante para algumas teorias neo-platônicas cujos diálogos podem ser resolvidos num entendimento gnóstico da própria obra. Atentos para isso, acreditamos que seja interessante retomar a proposição de Fiama Hasse Pais Brandão em "o texto de Joao Zorro":

Levando ao limite, homenagem, o gesto da escrita, posso atribuir em meus textos

a joao zorro. Existimos sobre o anterior. O movimento da escrita e da leitura

exerce-se a partir da menor mutabilidade aparente da pedra e da maior mutabilidade da grafia. O progresso dos textos é epigráfico. Lápide e versão, indistintamente.

O que nos permite observar que a contenção da própria escritura pode ser radicalizada ou destituída para que possam atender ao "progresso dos textos". E na medida em que "existimos sobre o anterior", devemos considerar que a voz dos poemas de Bernardim também seja um modo de leitura 
que define a lápide na qual os poemas adormecem e, contudo, enraízam para a cultura da versão (ainda que lapidada) de suas teses, como confirma o próprio Helder Macedo no início de Do significado oculto da Menina e Moça. Ou seja, a anterioridade dos poemas de Ribeiro justificaria a revisitação de vários lugares recorrentes no Saudades.

O que nos convém, além disso, é o que Macedo sugere acerca das personagens femininas da Menina e da Dona do Tempo Antigo ao validar a idéia de que ambas constituem um núcleo cuja essência é a situação de saudade e tristeza por que passam. A partir dessa observação, tencionamos verificar quais são os desdobramentos das personagens femininas no texto de Bernardim. Ainda de acordo com o próprio Helder Macedo, a relevância dos papéis femininos é de fato contundente, já que parecem concentrar um poder notáve na narrativa, bem como justificaria toda uma interpretação que quisesse (re)levar e (re)velar a função espiritual da mulher que em linhas gerais significaria o seguinte:

Esta visão niilística da terra como uma eterna prisão da alma não pode ser explicada pela leitura do poema como a elegia que também é à amada morta a qual, símbolo da sua "vontade", literalmente foi soterrada. Dentro de uma concepção espiritualizante do amor, a morte da amada - que é só a morte do seu corpo - não pode significar o fim da iluminação e pelo contrário, pode até acentuá-la. É o que acontece em Dante, Petrarca e no próprio Bernardim em, por exemplo, o significado que a morte de Belisa tem para Lamentor. É da perda de uma iluminação interior previamente alcançada através da amante morta que Bernardim está a falar neste poema: uma perda que não foi causada, mas que foi tornada irreversível pela sua morte?

Dessa forma, parece importante notarmos que as figuras femininas adquirem um efeito de iluminação do texto bernardiniano que sugere não só a iluminura textual como também o papel de força motriz do entendimento de cada par das três histórias. De outra forma: Belisa, Aónia e Arima constituem os núcleos das células de suas três histórias atreladas a Lamentor, Bimarder e Avalor. E mais: elas referenciam também o que já fora anunciado pela própria Menina e pela Dona do Tempo Antigo, já que suas trajetórias são sim a de opção pelo exílio, pela errância ou pelo silêncio. A morte de Belisa é, com alguma certeza, o tópico que desencadeia textualmente Aónia e Arima como constelações que trazem os seus respectivos cavaleiros devotados.

Ocorre que também a causa da iluminação de Lamentor é interrompida não só pela morte de Belisa, como anunciada pela própria na ocasião do sonho em que profere "sonhava, senhor, que estávamos vós e eu presos por um fio e eu cortava-o, e que vos não via mais" ${ }^{\prime 10}$ e posteriormente a perda da luminosidade
10. MACEDO. Do significado oculto da Menina e Moça, p. 47. 
12. RIBEIRO. Menina e Moça ou Saudades, p. 110.

13. MACEDO; RECKERT. Do Cancioneiro de Amigo. é referendada pela fala do próprio Lamentor que indica "Heivo-lo, senhora, de confessar, ainda que nisso force minha condição, que nem dizer-vo-lo nem cuidá-la quisera: houve menencória.." ${ }^{11}$

O que não seria então a menencória de Lamentor senão aquilo que desvia o sujeito da luz, fustigando-o no líquido escuro, cuja palavra em sua forma arcaica revela ainda o significado que qualquer dicionário etimológico oferece: melancolia, cuja fusão é a soma dos radicais gregos bílis (koria; kolia) + negra (melanós)? Parece, desse modo, que a melancolia talvez seja um outro tópico que funciona semanticamente nesse universo paralelístico do qual também se partiu para compreender que ordenações estilísticas podem ser encontradas no Menina e Moça. Esse espaço concedido ao lugar melancólico pode também ser interpretado com mais um dado que garante semanticamente aquilo que Elsa Gonçalves em A Lírica Galego-Portuguesa ${ }^{12}$ chamará de paralelismo conceitual. Em outras palavras: variação e repetição sistematizam a técnica fundamental das cantigas de amigo, cujo movimento é não só de caráter estilístico, mas léxico e mormente, semântico. De outro modo, o próprio Macedo na introdução crítica à edição que faz do Menina e Moça, em 1999, afirma:

Pela sua estrutura paralelística a Menina e Moça poderia, como qualquer cantiga de amigo, continuar ad infinitum ou em qualquer altura ser interrompida depois de definido o seu ter- ritório semântico, como de facto foi. Que era de esperar que fosse continuada, julgo que não pode haver a menor dúvida, mas que a sua organização estrutural também tenha permitido deixá-la em aberto sem prejuízo do significado nela codificado, parece uma originalidade adequada a quem a tivesse escrito sem saber se poderia terminá-la, como aliás é sugerido, através da narradora, logo nas primeiras páginas. Porque a final convergência que, com uma forma complexa de leixa-pren, dá à novela a sua profunda unidade semântica, é aquela que associa a Menina, enquanto narradora do livro, com Bernardim Ribeiro, enquanto seu autor ${ }^{13}$

Isto levará o crítico português a posteriormente atrelar a idéia de que essa extensiva cantiga de amigo que pode ser a Menina e Moça, para além da clara proposição que o Saudades seria um marco de novo gênero do Renascimento, ou nas palavras de Salgado Júnior, citado por Macedo, que tal livro seria o "Decâmeron Sentimental" europeu. Nesse ponto, a relação com a obra boccacciana residiria no fato de ambas sugerirem a fixação de um novo gênero, cujo contexto traria necessariamente reflexões sobre uma ordem de transição que também se operacionaliza a partir do fim da Idade Média para a o advento de uma nova concepção de mundo que o trecento ( $1^{\text {a }}$ fase do Renascimento, de acordo com Sevcenko) foi capaz de fixar a partir de moldes anteriormente expostos pela geração de Dante, por exemplo.
14. RIBEIRO. Menina e Moça ou Saudades, p. 66
EM TESE

BELO HORIZONTE

v. 19

N. 3

SET.-DEZ. 2013

PEQUENO. Acessos, sentidos e significados para Menina e Moça [...] p. $42-53$ 
Dessa forma, o entendimento do Menina e Moça poderia ser hipotetizado não só nas influências claramente atribuídas ao florescimento do gnosticismo na Península Ibérica, como também por meio da penetração dessas referências gnósticas na obra cabalística mais contundente desse momento epocal de transição: o Zohar ou Livro do Esplendor. Para Helder Macedo, é possível concluir portanto, que o cabalismo ibérico era amplamente difundido no contexto histórico ao qua pertence Bernardim, e que por conta disso haveria uma linhagem feminina dentro do Menina e Moça que somente o pressuposto cabalístico seria capaz de interpretar.

Para isso, Macedo opta por cotejar a Chéquina judaica à própria alegoria da menina e da dona do tempo antigo, conferindo a ambas duas faces de uma mesma matriz divina que fosse responsável pela mediação entre a mística e a terra., o que justificaria portanto o investimento por parte de Bernardim em relação ao exílio feminino. Outrossim, a progressão da religiosidade e da eloqüência do silêncio nessas personagens são dados importantes para que as leiamos de forma mais eficiente, conforme demonstra o próprio Helder Macedo ao observar:

Dos quatro amantes, a narradora consistentemente insiste na perfeição de Arima desde o momento do seu nascimento. E parece também claro que, graças a ela, Avalor conseguiu re- dimir a sua alma. Já o destino de Bimarder após a iluminação provocada por Aónia parece ficar em aberto dentro do tempo da narrativa da Dona ${ }^{14}$.

Consequentemente, podemos verificar que o devir da mudança ocorre ao longo do livro a partir de uma perspectiva progressiva, que nos leva a encontrar na última das histórias dos "dos dois amigos" que Avalor e Arima assumem no texto um grau de iniciação que Aónia e Bimarder não foram capazes de conjecturar. Ocorre, por conta disso, o perecimento embutido na transformação do próprio nome do cavaleiro que opta por romper a fidelidade a Aquelísia. Conscientes do amor que os unia, Aónia e Bimarder desenvolvem também uma sensualidade que não se verifica em nenhum momento entre Avalor e Arima, e prova disso é a repreensão que o 'amigo' sofre por parte da menos humana de todas as personagens bernardinianas:

Mas Arima, que muito bem o sabia e o viu vir, dissimulando fez que não vira, para ver em que parava aquilo. E determinou parar-se assim sem falar, que as coisas de Avalor, juntas ao seu alto segredo, a traziam tão desejosa de o saber como isto. E depois de se deixar estar assim um grande pedaço, que o sentiu tão pronto em a olhar, calando-se confirmou o que era, porque bem sabia ela que não podia aí haver amizade tão dissimuldada. E virando para ele o seu rosto À maneira de en-
15. MACEDO Do significado oculto da Menina e Moça, p. 90. 
16. RIBEIRO. Menina e Moça ou Saudades, p. 198. cedido com uma delicada flama, e fora de manencórea, esteve um pouco toda posta e os olhos postos nele, e quase virando-se com seu bem aposto corpo, indo-se, lhe disse: "Ou me vós tendes errado, Avalor, ou me andais a errar" ${ }^{15}$.

A gravidade da postura de Arima ratifica as observações aqui já feitas a respeito de sua relação com Avalor, na medida em que a dama, nesse caso, funciona constantemente como valor da pedagogia da iluminação.

Nesse ponto, o texto de Bernardim ganha em profusão e se multiplica por meio de uma beleza densa, por meio da qual é possível compreender a especificidade do amor daquela cujo nome é o anagrama de Maria. A austeridade de Arima ensina, portanto, a Avalor a iniciação na busca pela redenção que ela, como manifestação terrena da possível Chéquina - repositório da divindade que promove a consolação ao povo de Israel, encontrar a "fértil luz difusa que a penetra/ para nela executar o seu amor", segundo poema de Helder Macedo. Ou seja, a iluminação de Avalor só é possível mediante a impassibilidade actancial de Arima que, somente a partir de sua condição etérea, pode se valer do conhecimento e da mansidão extremamente enigmáticos, ainda que fertilizados pela difusa luz dos iluminados.

Finalmente, se utilizando de um critério que confere significado totalizante para a obra, Helder Macedo propõe em
Do significado oculto da Menina e Moça que o caráter cifrando do texto de Bernardim seja complementar às interrupções das histórias, cuja essência é o próprio devir. Com efeito, a leitura que Macedo faz aponta para um argumento por ele utilizado também na leitura que faz de Garrett ao trabalhar com o Viagens na Minha Terra. Tanto na obra quinhentista, quanto na obra oitocentista romântica, haveria, portanto uma aparente desconexão que é, segundo ele, deliberada em ambos os casos. Essa aparente falta de coesão que o fim abrupto do Menina e Moça aponta, executaria a pertinência desse tempo de exílios a que a própria esperança do 'povo de Israel' se encontrava escondida entre ribeiros de paisagens imprecisas. E isto nos leva a crer que Bernardim se utiliza do exílio também para fazê-lo funcionar como lugar em que as purgações se definem e se autenticam:

Como oportunamente se viu, no contexto da semiologia cabalística o valor metafísico da escrita tem por base a sua concepção como uma virtuosa sondagem, ou reconstrução, do "nome de deus" cujo conhecimento é a própria redenção. Dando à sua escrita uma atribuição feminina, Bernardim acentuou ainda mais esse valor metafísico, integrando, na própria estrutura do livro a função espiritual da mulher como personificação ou veículo da divindade e representação da comunidade no exílio. Através do livro procura, assim, - dentro da mais pura tradição cabalística, que determina que a salvação individual só 
17. MACEDO. Do significado oculto da Menina e Moça, p. 115. é possível a quem participe do destino colectivo da Comunidade, coisa que, implicitamente Bimarder não tinha feito, procurando um compromisso que o poupasse à fúria vingadora de Aquelísia - ao mesmo tempo acordar a sua comunidade para a fé, encorajando-a através de histórias exemplares a resisti às perseguições de que estavam sendo vítimas, e conseguir ele próprio a sua redenção pelo virtuoso exercício espiritual que consiste em escrevê-lo ${ }^{16}$.

Dessa forma, a escrita declara, no âmbito da literatura bernardiniana, não só uma função pedagógica, como sobretudo redentora, capaz de promover a redenção e refletir acerca não só dos múltiplos significados cabalísticos, mas também de discutir a própria condição humana que era, na época de Bernardim, colocada à prova pelas políticas totalitárias que a Inquisição estabeleceu e deixou como legado para o imaginário cultural português. A literatura, no entanto, marca a estratégia contra o poder e novamente sai imperiosa, e ilumina a selva escura à medida que torna coletivo o discurso do enigma do que não pode ser instrumentalizado.

\section{PARA (NÃO) CONCLUIR}

Pudemos verificar que o universo bernardiniano está atrelado não só às deflagrações renascentistas de que historicamente faz parte, como também reflete ainda traços incidentes de uma medievalidade que se manifesta a partir de usos do universo cavaleiresco, notabilizado nas características das cantigas de amor e amigo. Assim, traços como o paralelismo estilístico e conceitual, bem como a escrita em tom queixoso da Menina poderiam funcionar como ponto de partida para a compreensão da estrutura total do livro.

Mas além disso há também que se observar que o livro se dá num ciframento, para cujo significado devemos considerar a mística da época, e mais precisamente aquela que envolve o fato de a obra ter sido impressa na oficina de um editor engajadamente preocupado em divulgar, ainda que sub-repticiamente, as visões do povo judaico. Cabalisticamente, a aproximação entre o Menina e Moça é feita sob a leitura do Livro do Esplendor, que traz à tona uma consistente valoração da figura feminina, que no livro de Bernardim se destaca por meio da contínua sacralização das mulheres.

Consequentemente, ainda que não possamos categorizar o livro de Bernardim Ribeiro como legítimo romance ou longo poema em prosa, é possível lê-lo a partir de uma ótica que enobrece o seu discurso e o potencializa a funcionar como linguagem que penetrou na estrutura intersticial do poder e foi capaz de, nele, executar o seu amor.

\section{REFERÊNCIAS}

AGAMBEN, Giorgio. O Fim do Poema. In: Revista Cacto, São Paulo, 2002. 
GIL, Fernando \& MACEDO, Helder. Viagens do Olhar. Lisboa: Campo das Letras, S/D.

GONÇALVES, Elsa \& RAMOS, Maria Ana. A lírica galegoportuguesa. Lisboa: Comunicação, 1983.

HUE, Sheila Moura. Antologia de Poesia Portuguesa - século XVI. Rio de Janeiro: Sette Letras, 2005

MACEDO, Helder. Do significado oculto da Menina e Moça Lisboa: Moraes Editores, 1977.

MACEDO, Helder. Viagem de Inverno. Lisboa: Editorial Presença, 1994.

MACEDO, Helder \& RECKERT, Stephen. Do Cancioneiro de Amigo. Lisboa: Assírio \& Alvim, 1996.

SEVCENKO, Nicolau. O Renascimento. Campinas: Editora Unicamp/Atual, S/D.

SILVEIRA, Jorge Fernandes da. Lápide \& Versão: ensaios sobre Fiama Hasse Pais Brandão. Rio de Janeiro: Bruxedo, 2006.

RIBEIRO, Bernardim. Menina e Moça ou Saudades. Lisboa: Publicações Dom Quixote, 1999. 